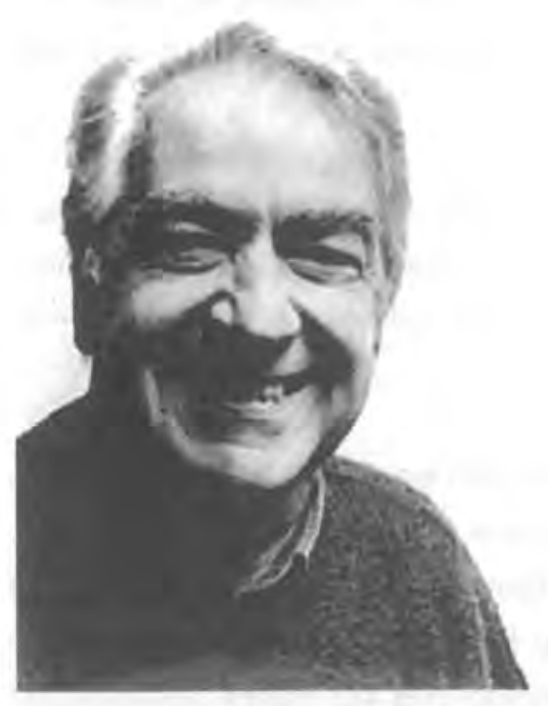

\title{
Las raíces de Maqroll
}

\section{Giulio Guarducci}

M aqroll el Gaviero es Álvaro Mutis que se mira al espejo, el espejo de una vida que es literatura. Evitando adentrarse en las problemáticas congresuales del doctor Lacan para desvelar este enésimo milagro de la creación artística, el caso mutisiano necesita otro análisis hermenéutico.

Vivo ciudades solitarias en donde los sapos mueren de sed. Me inicio en misterios sencillos elaborados con palabras transparentes.

Y giro eternamente alrededor del difunto capitán de cabellos de acero. Mías son todas estas regiones, mías son las agotadas familias del sueño. De la casa de los hombres no sale una voz de ayuda que alivie el dolor de todos mis partidarios. ${ }^{1}$

Esta voz lírica de Álvaro Mutis toma forma desde sus primeros tentativos poéticos, que maduran paralelamente a la experiencia de Mito, la revista del amigo y coetáneo Jorge Gaitán Durán, que «limpió el clima provincial de la cultura colombiana» ${ }^{2}$ tras Piedra y Cielo. Poemas como «El miedo», «Una palabra» o «La

'Mutis, Álvaro, «El miedom. En Los elementos del desastre. Buenos Aires, Losada, 1953, p. 42.

${ }^{2}$ Álvaro Mutis en una entrevista de José Miguel Oviedo y Alfredo Barrenechea (1974). Mutis, Álvaro. Poesiay prosa. Edición de Santiago Mutis. Bogotá, Colcultura, 1981. 
creciente» revelan un yo poético que aún está intimamente ligado a su autor: lleva consigo los rasgos distintivos de un pasado y un presente comunes, de una vida compartida:

Tras el agua de repente enriquecida con dones fecundísimos se va mi memoria.

Transito los lugares frecuentados por los adoradores del cedro balsámico, recorro perfumes, casas abandonadas, hoteles visitados en la infancia, sucias estaciones de ferrocarril, salas de espera.

Álvaro Mutis transcurre su infancia en Europa, entre Bruselas y París, rodeado de lujos y de todos los privilegios ofrecidos por la carrera diplomática de su padre, en una verdadera y propia «vida a la Barnabooth», como él mismo la ha definido. El francés se convierte en su segunda lengua y Francia en su patria de elección. Asimismo, mantiene un estrecho vínculo con sus raíces colombianas cruzando todos los veranos el gran océano Atlántico hacia la hacienda de sus abuelos maternos, en la región del Tolima, entre los ríos Coello y Cocora, lugares míticos que enmarcarán sus versos y que cuyo eco resonará más tarde en sus novelas.

Estas vitales premisas se funden, mutatis mutandis, con los siguientes y atormentados acontecimientos que modifican el curso de aquel río en crecida que es el destino del poeta: la muerte repentina del padre, el retorno forzoso a Colombia, la pérdida de la hacienda de Coello, el desarrollo tortuoso de las primeras experiencias laborales y, finalmente, el exilio colombiano. El poeta se confiesa una vez más en «La creciente»:

El rumor del agua se apodera del corazón y lo tumba contra el viento. Torna la niñez...

¡Oh juventud pesada como un manto!

La espesa humareda de los años perdidos esconde un puñado de cenizas miserables.

Llegados a este punto se puede intuir cómo la voz poética de Álvaro Mutis fluye directamente de su memoria, de su conciencia despertada por el dolor y la

"Mutis, Ảlvaro. «La crecientes. En Gli plement del disastro. Edición de Martha Canfield. Florencia, Le Lettere, 1997, p. 30. Fl poema en mención fue publicado originariamente en V/ida (1947). 
laceración, del mismo proceso de remoción psicoanalítica realizado por la escritura, que en otro lugar ha creado un Zeno (La conciencia de Zeno, de Italo Svevo) o un Stephen Dedalus (Retrato del artista adolescente, de James Joyce).

«Maqroll es sin lugar a dudas una parte de mí; pero sobre todo es aquello que pude ser y no he sido, es aquello que tuve miedo de sen. ${ }^{+}$Mutis se da cuenta de la importancia existencial de su alter ego mucho antes de su importancia literaria: Maqroll es un amigo, un compañero, una cura durante las noches de insomnio y durante los ataques de vacío de una «vida inauténtica», a los que una sensibilidad madura está más sujeta. Estas noches mutisianas de insomnio son puertas de percepción esenciales donde la voz no brota solamente del puro flujo de conciencia, por otra parte no siempre identificable, sino, sobretodo, de un lenguaje onírico, sonámbulo, exquisitamente nocturno que incluye a Mutis entre los representantes del Surrealismo. Además, la noche es un momento propicio para la metamorfosis, para la transformación mágica, cuando una voz cede el puesto a la otra, cuando uno se convierte en el otro, según la más antigua tradición esotérica. De hecho, Maqroll, y con él su mundo narrativo, se revela en estado de semivigilia preferiblemente cuando la luz del día amortece. Así termina «La creciente»:

Llega la noche y el río sigue gimiendo al paso arrolladorde su innúmera carga [...].

Hace calor y las sábanas se pegan al cuerpo. Con el sueño a cuestas, tomo de nuevo el camino hacia lo inesperado en compañia de la creciente que remueve para mí los más escondidos frutos de la tierra.

Aún más, atravesando los diferentes Nocturnos, en el poema «La visita del Gavieron de la antología Los emisarios (1984), encontramos un Maqroll paciente que espera el momento ideal para su enésima confesión: «Llevó una mecedora al corredor que miraba a los cafetales de la orilla del río y se sentó en ella con una actitud de espera, como si la brisa nocturna, que no tardaría en venir, pudiera traer un alivio a su profunda pero indeterminada desventura.»

Esta composición, junto con «El Cañón de Aracuriares, en la edición original del Fondo de Cultura Económica, era distinta tipográficamente a los otros por estar escrita en cursiva, como si el autor hubiera querido subrayar su especificidad

'Tbidem, p. 275. La traducción es mia.

'Tbidem, pp. 156 y 168. 
de fragmento narrativo vinculado íntimamente a la figura del Gaviero, y no solo lo poético en el sentido de mera proyección lírica de su ego. Confirma esta suposición el hecho de que los dos fragmentos fueron publicados como apéndice en la primera novela de Mutis, La nieve del almirante (1986), que inició la afortunada saga de Maqroll.

Porque, al fin de cuentas todos estos oficios, encuentros y regiones han dejado de ser la verdadera substancia de mi vida. A tal punto que no sé cuáles nacieron de mî imaginación y cuáles pertenecen a una experiencia verdadera. Merced a ellos, por su intermedio, trato, en vano, de escapar de algunas obsesiones, éstas sí reales, permanentes y ciertas, que tejen la trama última, el destino evidente de mi andar por el mundo.

Este es un punto crucial en «La visita del Gaviero»: incluso el lector más experto se siente desorientado en el atribuir este enunciado a Mutis o a Maqroll. Antes de excavar la sutil membrana que envuelve de fascinación la unión alquímica de ambos es mejor disipar la duda y adentrarnos en aquella noche epifánica que develará el misterio de la creación artística y nos ofrecerá a Maqroll en su esencia.

El Gaviero guardó silencio por un buen rato, hasta cuando cayó la noche con esa vertiginosa tiniebla con la que irrumpe en los trópicos. Unas luciẻrnagas impávidas danzaban en el tibio silencio de los cafetales. Comenzó a hablar de nuevo y se perdió en otra divagación cuyo sentido se me iba escapando a medida que se internaba en las más oscuras zonas de su intimidad. De pronto comenzó de nuevo a traer asuntos de su pasado y volví a tomar el hilo de su monólogo.

Maqroll el Gaviero nace ya viejo de la pluma de Álvaro Mutis, cuando éste tenía poco más de veinticinco años: nuestra premisa lo había anticipado. Es salvado por el anonimato muy tempranamente, como si el nombre consagrase su identidad de la misma manera que las más antiguas figuraciones míticas," y es así bautizado en el poema "Oración de Maqroll", de la antologia Los elementos del desastre (1953). Más allá del texto, el epígrafe resulta partícularmente significativo al objetivo de nuestras investigaciones: «Tu as marché par les rues de chain», extraído

'Cassirer, Ernst. Lingnaggio e mito. Milán, II Saggiatore, 1961, p. 11. 
de Babylone de René Crevel, uno de los primeros escritores surrealistas. Dicho epígrafe arroja luz sobre más de un indicio con respecto al origen de Maqroll, ante todo, sobre su carácter distintivo de búsqueda, de viaje, de camino, que pasa a menudo a través del cuerpo, los instintos, el acto sexual: la mujer es conocimiento.

Supo, por ejemplo, que la carne borta las heridas, lava toda huella del pasado, pero nada puede contra la remembranza del placer y la memoria de los cuerpos a los que se uniera antaño.

Aprendió que hay una nostalgia intacta de todo cuerpo gozado, de todas las horas de gran desorden de la carne en donde nace una verdad de substancia especial y sobre la que cl tiempo no ticne ascendiente alguno.

Las mujeres cómplices de Maqroll, como, por citar algunas, Flor Estévez, Ampato María o Dora Estela, en las novelas La nieve del almirante (1986), Un bel morir (1989) y Amirbar (1990), respectivamente, se configuran como «variaciones de su destinon," ampliaciones de su mundo, vehículos de conocimiento interior.

El nombre de René Crevel nos introduce, por el contrario, en el escenario del Surrealismo, tablas que seguramente ha pisado el primer Mutis, pero, más en general, nos introduce en el panorama de la cultura en lengua francesa, linfa vital de los estudios y de las lecturas del autor. Se dice, preferentemente, que Maqroll es un nombre inventado que no se identifica, aparentemente, con ninguna lengua ni con ninguna nación. Es un exiliado, un desarraigado de cualquier forma terrestre; su único hilo conductor parece ser el agua, génesis benigna de su existencial errat. Él es un Gaviero, es decir, el marinero de la cofa, aquel que está por encima y ve antes que los demás hombres; los ritmos biológicos y episódicos de su vida están escandidos por el mar, por sus tempestades, por el ascenso y descenso de la marea. Bajo la égida de la Wirkungsgeschichte' gadameriana, entra en causa el antecedente literario par exellence: Charles Baudelaire. En la edición de 1861 de Les fleurs du mal, el poema «L'homme et la men» recita estos primeros versos, que parecen invocat a Maqroll:

Mutis, Álvaro, «Fin el riom. En Gli elementi del disastro, p. 64.

"Morales Saravia, José, „Poesía y prosa en Alvaro Mutis». En Kohut, Karl (ed.), Literatura colombiana bog, Imuaginación y barbaric Frankfurt y Madrid, Zentralinstitut für Lateinamerika-Studien der katholischen Universität Eichstätt, 1994, p. 270.

"En castellano, uhistoria de los efectosn. 
Homme libre, toujours tu chériras la mer!

L.a mer est ton miroir; tu contemples ton âme

Dans le déroulement infini de sa lame,

Et ton esprit n'est pas un gouffre moins amer."'

Pero es, seguramente, la obra maestra (Le voyage», que cierra la última sección de la obra, la que influencia genéticamente el nacimiento del marinero mutisiano. Es el canto de las almas libres, de los puros de corazón que desahogan en el viaje por mar la inefable necesidad de desafio y la sed terrestre nunca apagada, las mismas que un tiempo fueron atributos de Odiseo:

Un matin nous partons, Ie cerveau plein de flamme,

Le coeur gros de rancune et de désits amers,

Et nous allons, suivant le rythme de la lame,

Berçant notre infini sur le fini des mers:

Les uns, joyeux de fuir une patrie infâme;

D'autres, l'horreur de leurs berceaux, et quelques-uns,

Astrologues noyés dans les yeux d'une femme,

La Circé tyrannique aux dangereux parfums."

En la segunda parte del poema se canta sobre una voz «loca» que proviene de la cofa: es el grito maqrolliano del Profeta-Gaviero que anuncia un nuevo advenimiento, la esperanza de una dicha que muda inmediatamente en la amarga constatación de la desilusión: «Une voix de la hune, ardente et folle, crie:/ "Amour...gloire...bonheur!" Enferl c'est un écueill»."

Desilusión y desencanto son palabras recurrentes en el diccionario de las aventuras de Maqroll, tanto es así que él mismo parece estar acostumbrado a los resultados desalentadores de sus empresas, como el negocio de la madera que se fue todo en humo durante la búsqueda de las quiméricas serrerías en $I$ a nieve del almirante, o bien el intento fallido de enriquecerse con oro en las minas de Amirbar. A

\footnotetext{
"scmpre il mare, uomo libero, amerail/ perchè il mare ć il tuo specchio; tu contempli/ nell'infinito svolgcrsi dell'onda/ l'anima tua, e un abisso é il tuo spirito/ non meno amaroo. Baudelaire, Charles. Les flewrs du swat. Traducción de Luigi de Nardis. Milán, Feltrinclli, 1997, p. 33.

"wNoi parúamo all'alba, colmo/ il cervello di tiamma, il cuore gonfio / di rancote e di amari desideri, /e andiamo sul finito degli oceani/ cullando l'infinito nostro, l'onda/ seguendo nel suo ritmo: lieti, gli uni,/ di fuggire una patria infame, gli altri,/ l'orrore della loro terra, ed altri,/ astrologhi annegati dentro gli occhi/ d'una donna, i profumi perigliosi/ di una Circe tirannicas. Ibledem, p. 253.

12."Grida, ardente, / dalla coffa una voce folle: "Amore.../ghoria... felicità...P" Malcdizioncl,/ c uno scogliolm. Ibidem, p, 255.
} 
pesar del desastre aparente, conseguimos entender de inmediato el significado de la misión: testimoniar a través de sí mismo la vanidad de las acciones humanas y consecuentemente contar sus desventuras para impedir a los demás seguir su nefasto ejemplo, tal y como cantaba The Rime of the Ancient Mariner (1798) de Samuel T. Coleridge. Entonces, el viajero de Baudelaire y el de Mutis son investidos con la misma carga de custodios de los destinos humanos, insondables como los mares que atraviesan:

Étonnants voyageurs! Quelles nobles histoires Nous lisons dans vos yeux profonds comme les mers! Montrez-nous les écrins de vos riches mémoires, ces bijoux merveilleux, faits d'astres et d'éthers. ${ }^{13}$

Según la feliz fórmula de Marcel Raymond, Les fleurs du mal es la fuente viva de la corriente poética contemporánea, ya sea que esta corra por la vertiente de los poetas-artistas, Baudelaire, Mallarmé, Valéry, o que fecunde el terreno fértil de los poetas-videntes, Rimbaud, los surrealistas y hasta los más recientes buscadores de aventuras." Siguiendo este segundo haz, pienso proseguir mi estudio.

A menudo, me he preguntado si existe un antecedente biográfico de Maqroll además del literario. Naturalmente, excluyo la vida de Álvaro Mutis porque son poquísimas las concordancias efectivas; por otra parte, él mismo ha afirmado a este propósito: «Atravieso experiencias que yo cuento, salen a la luz rasgos de carácter que lo completan y que derivan de un vivido que es suyo, no mín. ${ }^{15}$ La reflexión ha recaído sobre Arthur Rimbaud, confirmada, incluso, por la predilección de Mutis hacia este autor, como se aprecia en el poema «Estela para Arthur Rimbauds," en Los Emisarios (1984), y por el epígrafe del «Nocturno VII»; "Voici le temps des assassins»," en la antologia Un bomenaje y siete nocturnos (1987). Maqroll y Rimbaud son dos seres míticos arrojados a una «caza espiritual» insaciable que pisa, sorprendentemente, las mismas etapas de desarrollo. Arthur Rimbaud, thombre de las suelas de vienton, según Verlaine, quema muy joven su

\footnotetext{
" $\mathrm{O}$ sorprendenti/ viaggiatoril Che nobili racconti/ vi leggiamo negli occhi, come mari/ profondil Su, mostrateci glit scrigni/della ticca memoria, quei gioielli/ meravigliosi, fattid'astri c d'eteren. 1bidem.

"Raymond, Marcel. De Baudelairs au Surrealisme. Paris, José Corti, 1947.

${ }^{15}$ Conversación con Álvaro Mutis en Gli elementi del disastro, p. 298. La traducción es mía.

"Tbidem, p. 178.

"Ibidem, p. 242.
} 
creatividad poética para terminar su vida como hombre de aventura, siempre en lugares diversos y topando con oficios diversos, al igual que Maqroll: preceptor, marinero y descargador de puerto, voluntario en el ejěrcito holandés y, luego, en África, dedicado a tráficos ilícitos. Muere a causa de un tumor en la pierna en un hospital de Marsella. Si bien el propio Mutis ha reivindicado, en sí mismo, como hecho autobiográfico la herida en la pierna de Maqroll, ${ }^{i \star}$ toda la ecuación es reveladora: Rimbaud está en las venas de Maqroll.

Se ha dicho que el demonio de la revuelta y de la destrucción de Rimbaud ha dado inicio al «tiempo de los asesinos»; pero su intérprete más agudo ha sido Lautréamont, numen tutelar del Surrealismo, como escribió André Breton en el Manifiesto de 1929. En sus célebres Chants de Maldoror(1868), el lenguaje poético evoca ciertas imágenes de las que, al parecer, Mutis ha tomado inspiración para su Maqroll: «Basta ya con este argumento. No ha pasado mucho tiempo desde que he vuelto a ver el mar $\mathrm{y}$ he pisado el puente de los navíos, $\mathrm{y}$ mis recuerdos son vivaces como si lo hubiese dejado ayen. "El mismo nombre de aMaldoron es sugestivo en referencia al Gaviero, no solamente por el sonido, sino también por el significado: «mal de aurora», incapacidad de vivir el día. El propio uso de una prosa poética "diabólica» de ambientación nocturna hace vincular a Mutis con Gaspard de la Nuit (póstumo, 1842) de Aloysius Bertrand, aunque la descendencia de Lautréamont sea más fértil, como ya había notado antes Octavio Paz." Maldoror y Maqroll comparten el dolor, la experiencia de la laceración: «He recibido la vida como una herida, y he prohibido al suicidio sanar la cicatrizm. "Sin embargo, en un determinado punto, Ducasse parece sugerir a Mutis la idea de la génesis de su álter ego: «Según lo que acabé sabiendo más tarde, he aqui la simple verdad: el prolongarse la existencia en aquel elemento fluido habia producido insensiblemente, en el ser humano que se había exiliado voluntariamente de los continentes pedregosos, mutaciones importantes, pero no esenciales, que había notado en el objeto que una ojeada pasablemente confusa me había hecho tomar [...] por un pezs. ${ }^{2}$ El amigo Dazet, que hacía de interlocutor personal en la primera redacción de los

\footnotetext{
"Thidem, pp. 300-301.

"Ducasse, 1sidore. Opere complete. Turín, Eỉnaudi, 1967, p. 33. La traducción es mia.

"Paz, Octavio. «Los hospitales de ultraman" (1959). En Puertas al campo. México, Universidad Nacional Autónoma de México, 1966, pp. 131-136.

${ }^{2}$ Ducassc, 1., ob. ci., p. 205. La traducción es mia.

"Ibídem, p. 293. La traducción es mia.
} 
Chants, es sustituido por las figuras de pulpo, tiburón, oso marino y otros, metonimias del bestiario personal de Lautréamont. Así, podemos preguntarnos si es posible que Maqroll también tenga una derivación semejante o si Mutis era consciente de ello en el momento de su bautismo. Aunque se haya inferido muchas veces que el nombre de Maqroll no tiene raíces, justamente como signo de su misión de "peregrino elegido por los díoses»," mi estudio traiciona esta cuestión. Sabernos que Álvaro Mutis ha surcado los mares innumerables veces a bordo de viejas naves mercantiles y modernos transatlánticos que batían banderas diversas, ya desde pequeño, acompañando a sus padres, como en la madurez, empujado por las necesidades laborales. El nombre de Maqroll nace, precisamente, del lenguaje marinero: el nombre de un pez, tal vez el apelativo familiar del joven mozo, retoma el sonido del grafema <maqroll $>$. En inglés, este mismo sonido ['makr]], escrito <mackerel>, significa «escombro», el pez azul símbolo del mar y de su proteica energía vital; incluso el francés <maquereau > y el italiano $<$ macarello $>$ se refieren al mismo pez. Todos derivan del holandés (los contactos de Mutis con esta área lingüística tuvieron lugar muy pronto, durante la época de su frecuentación infantil de Bruselas) <makreel>, kescombro», que a su vez procede del holandés medio <makelare $>$ y $<$ makelen>, "trafican", porquie se creía que el pez acompañaba a las anguilas en las migraciones y favorecía el acoplamiento. De hecho el italiano <macrò $>$ y el argot francés $<$ macro $>$ derivan del francés <maquereau>, en su acepción de "proveedores de amores ilícitos», otra característica peculiar de Maqroll, recordemos todas las aventuras eróticas de sus novelas, ahora ya comprensiblemente inherente a su esfera semántica además de a lo vivido mutisiano.

En la Metamorfosis de Ovidio, en el libro XIV, verso 159, aparece un tal Macareo, mítico compañero de Ulises, que el hado quiso relator de sus memorias y las de la desventurada tripulación de Ítaca. Aqueménides ruega a Macareo: «Mas ahora incluso tú, compañero mio amadísimo, cuenta las vicisitudes/ tuyas, de Ulises e del grupo que contigo se aventuró en el mans, ${ }^{4}$

Y Macareo, amarrado, habla del miedo en las playas de Circe tras las pesadillas de Antifate y del despiadado Cíclope. Como Maqroll, también es un

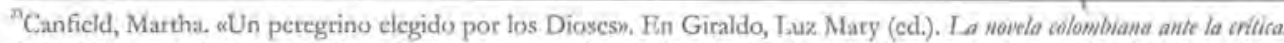
1975-1990. Bogoti, Centro Editorial Javeriano y Editorial de la Eacultad de Humanidades de la Universidad del Valle, 1994.

${ }^{20}$ Ovidio Nasone, Publia. Metamorfosi. Milán, Garzanti, 1995, p. 645, vv. 221-222. La traducción es mía.
} 
marinero con una historia de desventura a las espaldas y una amarga suerte de relato.

En su articulo «Un peregrino elegido por los Dioses»," Martha Canfield efectúa una reveladora confrontación entre las novelas Heart of Darkeness (1902), de Joseph Conrad, y La nieve del almirante (1986), de Álvaro Mutis, ya que muestra las mismas modalidades narratológicas en ambos textos (un narrador extradiegético y otro homodiegético) y fabulísticas (el mismo motivo del viaje en tierras salvajes, el remontar el río, el encuentro con los indígenas), y arroja luz sobre la alusiva asonancia de los nombres de los respectivos protagonistas, Marlow-Maqroll, subrayando una cierta filiación.

En búsqueda de otro ilustre antepasado de la literatura de los marineros, he colacionado el legado melvilliano, Moby Dick (1851). La configuración estructural de la obra es análoga a las precedentes: la novela es el relato de Ishmael, único superviviente de la furia de la ballena blanca, voz narrativa que se confunde entre las otras de la Pequod hasta hacer emerger con prepotencia la del capitán Ahab, figura satánica medida por el mismo rasero que Maldoror. Ahab acarrea sobre sí mismo el signo del sufrimiento, la pata de palo, la misma «llaga sintomática» ${ }^{3}$ de Maqroll; y como el Kurtz de Conrad y el Capi de Mutis, está destinado a perecer.

$\mathrm{Al}$ inicio de este estudio hermenéutico, habiamos adelantado que para conocèr a Maqroll habría sido necesario viajar dentro su conciencia, que és, àl mismo tiempo, la de su autor. Leyendo la prosa poética mutisiana, donde es más fuerte la voz del Gaviero, o mejor aún, las novelas, que han entrelazado alrededor de él una verdadera y propia saga," es natural recordar las aventuras, las evocaciones o las pesadillas no en relación a cada una de las obras, como enjauladas en secciones distintas, sino directamente asociadas a la figura de Maqroll, como si nos las hubiese contado él mismo, quizás, una noche en un bar de las Ramblas de Barcelona, en Rue de Capucines en París, o en el Ponte Vecchio en Florencia. Siguiendo las huellas del gestaltismo, podemos comprender cómo la percepción compleja que tenemos de Maqroll el Gaviero no nos ha sido donada por un único momento de su vida o de su memoria, sino por la distanciada y soñada visión global de su

"Canficld, Mlartha, ob, cit, p. 161.

lbidem, p 166.

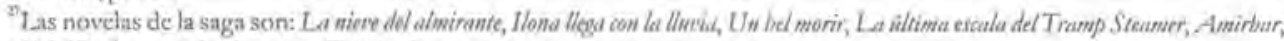
Abdul Bessbor, soñador de navios y Tolptico de matry tierna. 
odisea; de la misma forma en que el «Nocturno» de Chopin no vive en las singulares notas que lo componen, sino en el sublime abandono total a su melodía. La percepción compleja que tenemos de Maqroll el Gaviero no nos ha sido dada por un único momento de su vida o de su memoria, sino por la distanciada y soñada visión global de su odisea. La intertextualidad ${ }^{3}$ que se crea en el interior del palimpsesto maqrolliano, como he intentado demostrar, es el reflejo literario de nuestra percepción adquirida.

El viaje se detiene en el Modernismo. Fue a través de este movimiento que América Latina se preocupó, por primera vez, por recuperar sus raíces mediante un «renacimiento» que ya no habría seguido nunca más la dirección de las carabelas, sino que más bien habría producido una inversión de tendencia en la propagación cultural. La vida y obra de Álvaro Mutis, cuyo dinamismo se mueve de Europa a Colombia y, luego, desde alli, al resto del mundo, confirman este proceso: Maqroll el Gaviero es su símbolo. *

\footnotetext{
Aqui se entiende por intertextualidad el conjunto de relaciones que uacercan un texto tanto a otros textos dej mismo autor como a los modelos literarios explícitos o implicitos a los que se pucde hacer referencias. Marchese, Angelo y Joaquin Formadellas. Diccionario de retórica, critica y lerminología literania. Barcelona, Ariel, 1994, pa. 217, Para mí, el término üntertextualidad" puede traducie muy bien mi estudio hermenẻutico de este viaje imaginario por las raices de Maqroll.
} 